\title{
Design Simulation of Cll Resonant Dc-To-Dc Converter for Stand Alone Wind Energy System
}

\author{
M. Annamalai ${ }^{1}$, Member, IEEE, Dr. M. Vijaya Kumar ${ }^{2}$, Life Fellow, ISTE
}

\begin{abstract}
This paper deals with design and simulation of DC-to-DC converter for stand-alone wind energy system. The CLL resonant inverter system and DC- to- DC converter system are simulated using MATLAB simulink power system blocks. This converter has advantages like reduced transformer size, reduced filter size and current source characteristics. The Simulink circuit model for closed loop system is developed and the same is used for simulation studies. The simulation results are presented.
\end{abstract}

Index Terms-Converter, Resonant Inverter, DC to DC Converter, Mat lab.

\section{INTRODUCTION}

Small - scale stand-alone wind energy is increasingly viewed as a viable and sometimes preferred source of electrical energy. Consider, for example, remote villages in developing countries or ranches located far away from main power lines. Wind energy is a quiet alternative to remote diesel generation- generation that sometimes depends on excessive transportation and fuel storage costs- and an economically justifiable alternative to a grid connection. It has been shown that a remote load has only to be a matter of a few miles away from a main power line for a stand-alone wind generator to be cost-effective [1]. Wind turbines, however, are not always very efficient in the wind speeds that are most common to a region. Typically, wind energy systems are designed to be highly efficient in high wind speed and have a cut-off wind speed- below which no energy is captured. In remote locations where wind energy is used for battery charging, the energy lost below the cutoff wind speed could be used for trickle charging or maintaining a battery's fully charged state.

Wind turbines are most efficient when they are operated at one specific tip-speed to wind-speed ratio (TSR) [2]. Therefore, for the efficient capture of wind power, turbine speed should be controlled to follow the ideal TSR, with an optimal operating point, which is different for every wind speed. A typical, small-scale, stand-alone, wind electric system is composed of a wind turbine, a permanent-magnet generator, a diode bridge rectifier, and a DC power system.

In many small-scale systems, the DC system is at a constant DC voltage and is usually comprised of a battery bank, allowing energy storage, a controller to keep the batteries from overcharging, and a load. The load may be

\footnotetext{
${ }^{1}$.Research Scholar, Department of Electrical \& Electronics Engineering, Sathyabama University, Chennai, India (Email Id: annamalaimp@gmail.com).

${ }^{2}$.Professor, Department of Electrical \& Electronics Engineering, JNTU, AP, India (Email Id: mvk_2004@rediffmail.com).
}

DC or may include an inverter to an AC system. The load configuration is beyond the scope of this work.

Unfortunately, there can be significant problems connecting a wind generator to a constant DC voltage. At low wind speeds, the induced voltage in the generator will not be high enough to overcome the reverse bias in the diode bridge. At high wind speed, the electrical frequency increases and the reactive impedance of the generator will be high, while the impedance of the battery load will be low. In this case, the poor impedance matching will limit power transfer to the DC system [3]. In response to these problems, researchers have investigated incorporating a DC - DC converter in the DC link [4]-[7]. While allowing a constant dc voltage to the load, a DC - DC converter will allow the voltage at the output of a diode bridge rectifier to be controlled. In low wind speed conditions, the voltage may be lowered to prevent the dc link from reverse biasing the diode rectifier. Under high wind speed condition, the voltage may be increased, reducing I2R losses. In addition, adjusting the voltage on the dc rectifier will change the generator terminal voltage and thereby provide control over the current flowing out of the generator. Since the current is proportional to torque, the DC - DC converter will provide control over the speed of the turbine.

Control of the DC-DC converter may be achieved by means of maximum power point tracking [5] or by means of a pre-determined relationship between wind speed and rectifier dc voltage [6], [7]. Maximum power point tracking requires continuous variation of the dc voltage to determine whether the output power may be increased. This system is relatively complex and may have limited using tracking rapid changes to the system. The relatively high turbine inertia can cause a significant time lag between the changes to the DC -link voltage and any observed change in power. Use of a predetermined relationship between wind speed and voltage may also have difficulties. Accurate wind speed measurement is difficult and requires the use of a relatively expensive anemometer if it is to be used for system control. The system proposed in this work makes use of a predetermined relationship between generator electrical frequency and DC -link voltage.

This paper deals with a buck DC - DC converter that achieves high wind turbine efficiency across a wide range of wind speeds. The system is designed for use in remote location and, therefore, includes a simple control strategy and a fault- tolerant topology. The control circuit included fault detection and has been tested with a parallel redundant DC link. Previously published works [8], [9] demonstrated the ability of the control system to detect both open- and short-circuit converter faults and switch to a parallel converter without interruption of the supply. The literature 
[1] to [9] does not deal with the simulation of closed loop controlled DC-to-DC converter. This paper deals with simulation of closed loop controlled DC- to- DC converter.

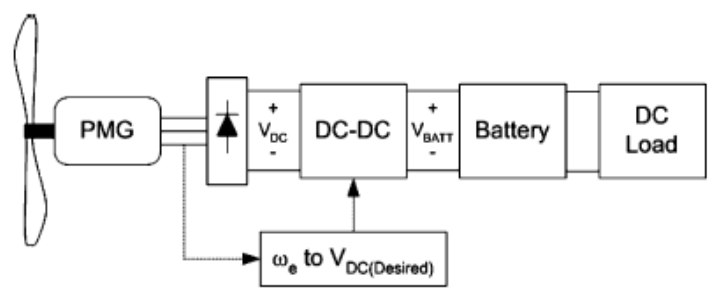

Fig. 1. Schematic diagram of the stand-alone wind energy system under consideration.

The system is represented in Fig.1 where $V_{D C}$ is a variable voltage and $\mathrm{V}_{\mathrm{BATT}}$ is a fixed DC voltage. System data are given below:

TABLE 1 WIND ENERGY SYSTEM DATA

\begin{tabular}{|c|c|}
\hline Effective Turbine Radius & $1.0 \mathrm{~m}$ \\
\hline $\begin{array}{c}\text { Phase to Phase Winding } \\
\text { Inductance }\end{array}$ & $3.3 \mathrm{mH}$ \\
\hline $\begin{array}{c}\text { Phase to Phase Winding } \\
\text { Resistance }\end{array}$ & $0.51 \mathrm{Ohms}$ \\
\hline $\begin{array}{c}\text { Peak per Phase Torque } \\
\text { Constant }\end{array}$ & $0.71 \mathrm{Nm} / \mathrm{A}$ \\
\hline Poles & 8 \\
\hline System Inertia & $1.2 \mathrm{~kg}-\mathrm{m}^{2}$ \\
\hline System Damping & $0.16 \mathrm{Nm} / \mathrm{kRPM}$ \\
\hline
\end{tabular}

\section{THEORETICAL APPROACH}

The fundamental equation governing the power capture of a wind turbine is turbine power, air density, the swept turbine area, the turbine coefficient of performance, and is wind speed. The coefficient of performance is a function of TSR, described by where is rotational speed, is the turbine radius, and is the wind speed. It is clear that (for this case) the maximum power captured by the wind turbine will occur when the TSR is approximately 7.5, corresponding to a 0.35 . A relatively small deviation on either side of this TSR will result in a significant reduction of the power available for conversion to electrical energy. Employing control of the rotational speed of the turbine allows the TSR to be controlled and the coefficient of performance to be maximized. Thus, in turn, the generated electrical energy may be maximized.

Control over the rotational speed is achieved by varying the generator terminal voltage. A simple understanding of the ideal steady-state relationship between terminal voltage and rotational speed may be obtained by considering a generator with a fundamental current in phase with terminal voltage and neglecting harmonic currents.

The generator-induced voltage and armature currents can now be obtained from the manufacturer's data by means of the governing torque and voltage equations. Now consider the fact that the terminals of the generator are connected to a diode rectifier. Neglecting for the time-being effects of commutation overlap (which may be significant), it may be assumed that the phase voltage and fundamental component of the armature current of the generator are in phase.

An approximation of the rectified dc-link voltage may be obtained using the standard equations for a three-phase fullbridge diode rectifier with line inductance. It is possible to obtain a prediction for DC-link voltage as a function of mechanical speed (or electrical generated frequency) and TSR. In the ideal case, the generator operates at the peak of the curve.

\section{Design CAlCUlation}

The following assumption are made, $48 \mathrm{~V} / 12 \mathrm{~V}$ transformer, fs $=20 \mathrm{KHz}$, fr $=56 \mathrm{KHz}, \varphi=10 \mu \mathrm{wb}$,

$\mathrm{Lr}=9 \mu \mathrm{H}, \mathrm{RL}=100 \Omega, \mathrm{r}=7 \mathrm{e}-4$.

Saturation is neglected.

Magnetizing current is neglected.

$\begin{array}{ll}\text { Using } & E_{1}=4.44 \times N_{1} \times \varphi \times f \\ \text { We obtain } & N_{1}=54 \\ \text { Using } & E_{2}=4.44 \times N_{2} \times \varphi \times f \\ \text { We obtain } & N_{2}=13 \\ \text { Using } & f_{r}=1 / 2 \pi \sqrt{L_{r} C_{r}} \\ \text { We obtain } & C_{r}=0.75 \mu F \\ \text { Using } & r=1 / 4 \sqrt{3} \times f \times C \times R_{L} \\ \text { We obtain } & C=100 \mu F\end{array}$

\section{Simulation Results}

DC-DC converter is modified by employing half bridge inverter in the place of full bridge inverter. This modification reduces number of transistors by two. DC-DC converter is shown in figure $3 \mathrm{a} .48 \mathrm{~V} \mathrm{DC}$ is converted into AC using half bridge inverter. Soft switching is obtained by introducing CLL circuit. $48 \mathrm{~V}$ AC is stepped down to $12 \mathrm{~V}$ $\mathrm{AC}$ by using step down transformer. The output of transformer is rectified by using a diode rectifier and capacitor filter. Scopes are connected to display the driving pulses, inverter output and DC output. DC input voltage is shown in figure $3 \mathrm{~b}$. Driving pulses for MOSFET are shown in figure $3 \mathrm{c}$. It can be seen that the pulses of M2 are shifted by $180^{\circ}$ with respect to the pulses of M1. The output of resonant inverter is shown in figure $3 \mathrm{~d}$. The secondary voltage of transformer is shown in figure $3 \mathrm{e}$. DC output voltage is shown in figure $3 \mathrm{f}$. It can be seen that the DC output is free from ripple.

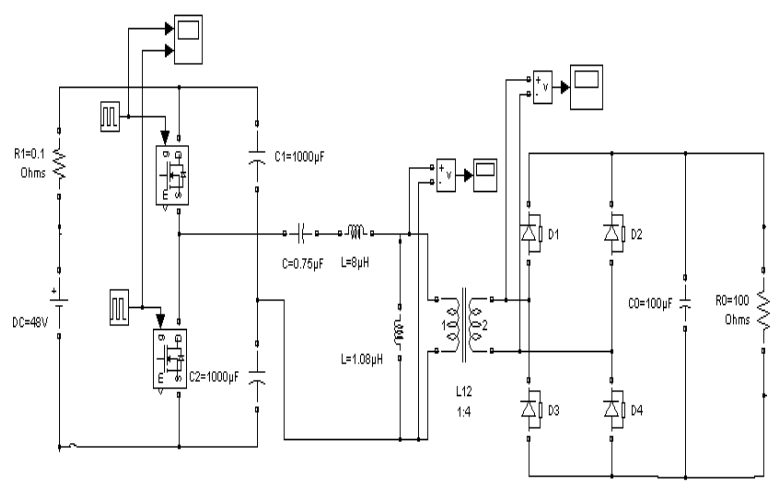

3a. DC-DC converter circuit 


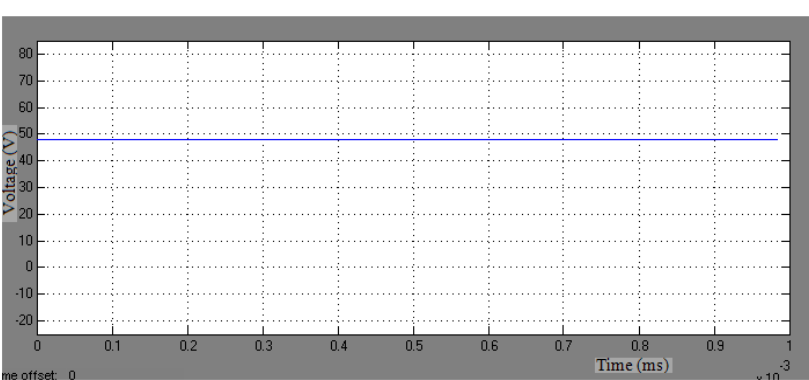

3b. DC Input Voltage

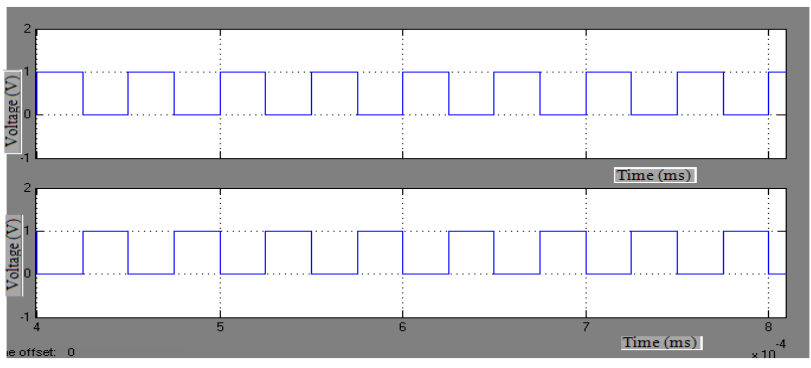

3c. Driving pulses for MOSFET

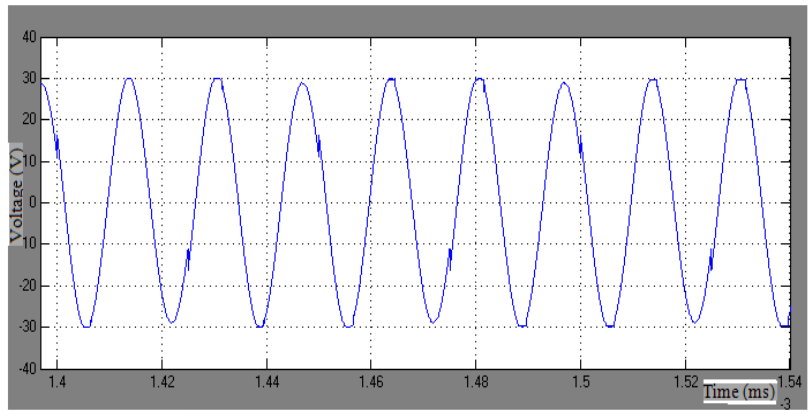

3d. Resonant Inverter Output

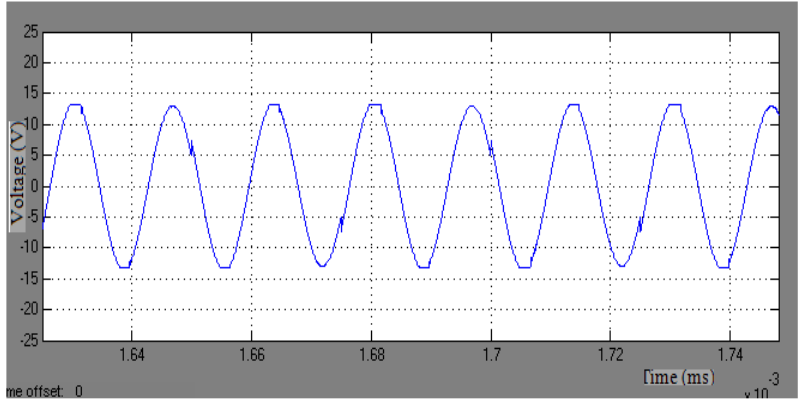

3e. Transformer Output

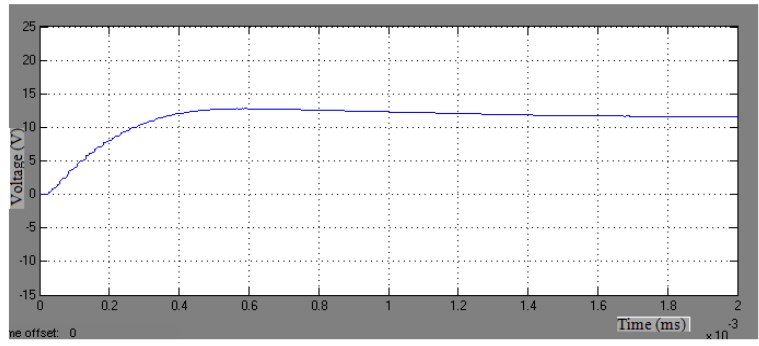

3f. DC Output Voltage

\section{Closed LoOP System}

Open loop system with disturbance at the input is shown in figure 4a. A step increase in input voltage is applied. The input voltage with disturbance is shown in figure $4 \mathrm{~b}$. The output voltage with disturbance is shown in figure $4 \mathrm{c}$. The output voltage also increases in open loop system. Closed loop system is shown in figure $4 \mathrm{~d}$. The output voltage is sensed and it is compared with the reference voltage of $5 \mathrm{~V}$. The error is given to a PI controller. The output of PI generates pulses with reduced width. When these pulses are applied to the MOSFET's in the output rectifier, the output reduces to the set value as shown in the figure 4e. Thus the closed loop system is capable of reducing the steady state error.

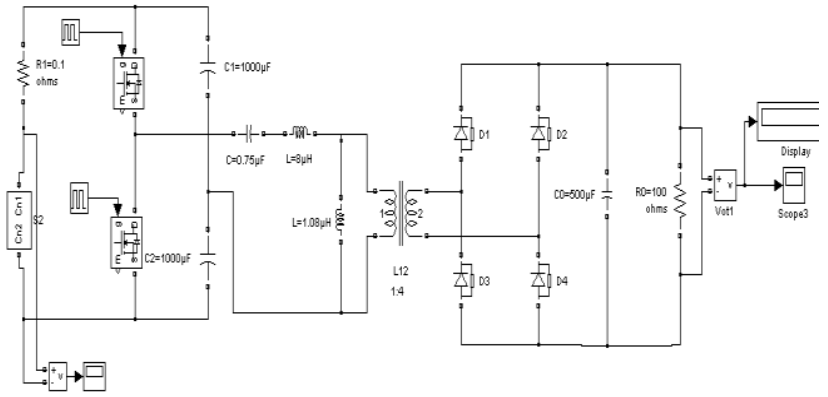

4a. Open Loop System with a Disturbance

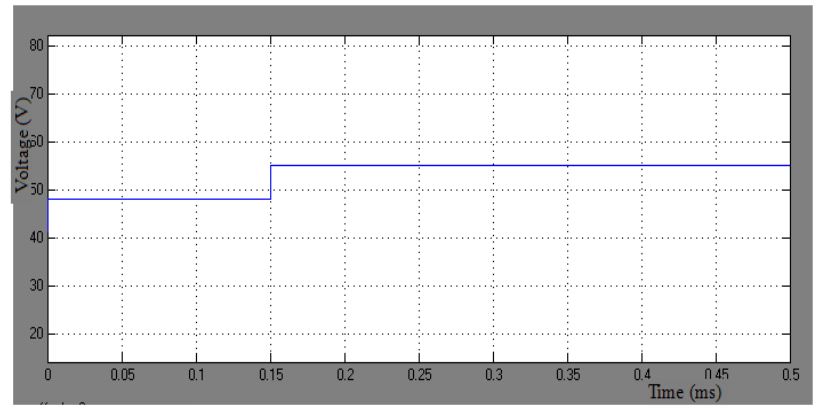

4b. Input Voltage with Disturbance

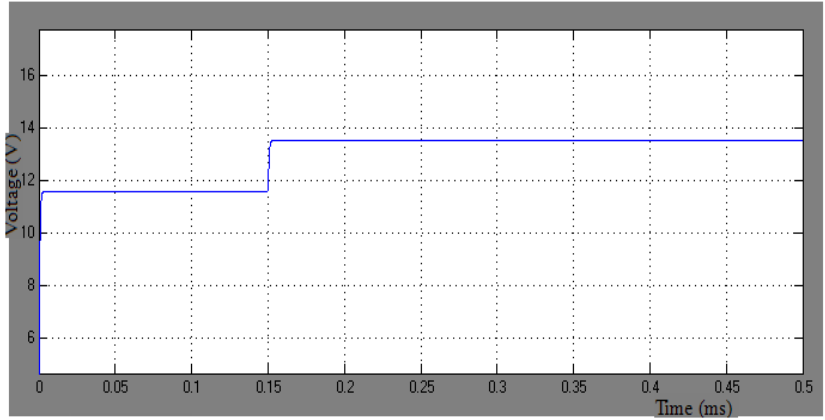

4c. Output Voltage with Disturbance

A.

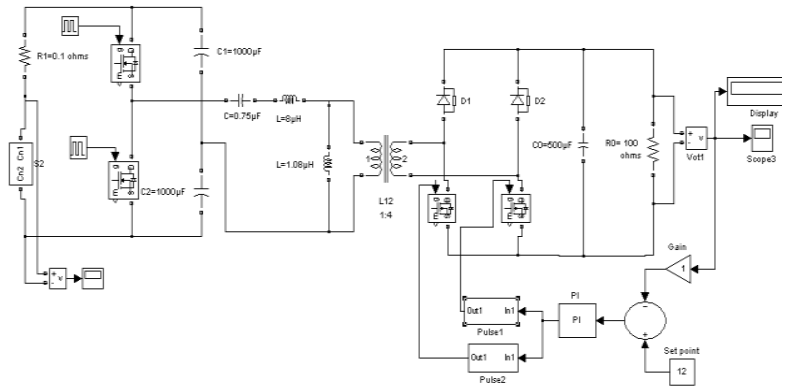

4d. Closed Loop System 


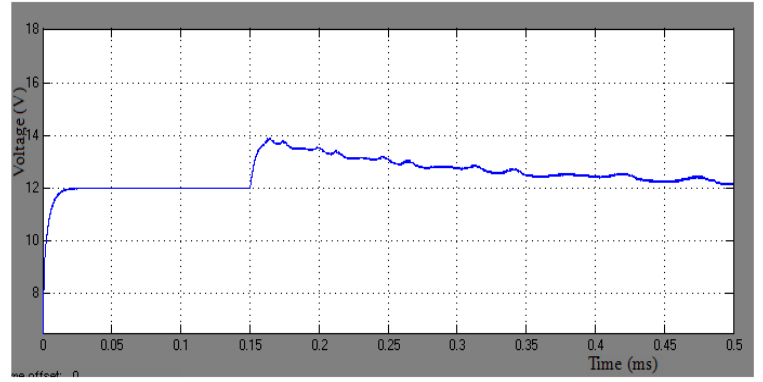

4e. Output Voltage Waveform with Disturbance

\section{CONCLUSION}

The open loop and closed loop controlled DC-DC converter systems are designed and simulated using MATLAB version 7.1 and the results are presented. This converter is popular due to reduced EMI, reduced stresses and high power density. The simulation studies indicate that CLL type DC-DC converter can be used with stand-alone wind generator. The simulation results are in line with predictions. Constant voltage can be maintained at the output of DC-to-DC converter by using a PWM rectifier at the output. Simulation results indicate the validity of closed loop model. The scope of this paper is the design and the simulation of the DC to DC converter. The hardware is yet to be implemented.

\section{REFERENCES}

[1] W. D. Kellogg, M. H. Nehrir, G.Venkataramanan, and V. Gerez, "Generation unit sizing and cost analysis for stand-alone wind, photovoltaic, and hybrid wind/PV systems," IEEE Trans. Energy Conversion. Vol. 13, pp. 70-75, 1998.

[2] S. Drouilhet, E. Muljadi, R. Holz, and V. Gevorgian, "Optimizing small wind turbine performance in battery charging applications," in NREL/TP-441-7808. Golden, CO: National Renewable Energy Laboratory, 1995.

[3] N. Yamamura, M. Ishida, and T. Hori, "A simple wind power generating system with permanent Magnet type synchronous generator," in Proc. IEEE Int. Conf. Power Electronics Drive Systems, vol. 2, Hong Kong, Jul. 27-29,1999, pp. 849-854.

[4] Mangesh "Analysis and design of LCL-T resonant DC to DC converter", IEEE trans.on IE 2005.

[5] S.Arul Daniel and N.Ammasai Gounden "A novel Hybrid Isolated Generating System based on PV fed Inverter assisted Wind-driven Induction Generators". IEEE Transaction on energy conversion, pp 416- 422, Vol. 19, No.2, June 2004.

[6] M. Arutchelvi and S. Arul Daniel, "Voltage Control of autonomous hybrid generation scheme based on PV array and wind-driven induction generators", Electric power components and systems, pp. 759-773, Vol.34, No.7, July 2006.

[7] M. Arutchelvi and S. Arul Daniel, "Composite controller for a hybrid power plant based on PV array fed wind-driven induction generator with battery storage", International Journal of energy Research, pp.515-524 Vol.31, April 2007.

[8] Hamin Tao, A.M Hendix, " Three port triple half bridge DC to DC converter with zero voltage switching" IEEE Transaction on Power Electronics, pp 782-792, 2008.

[9] S.H. Hosseni, R. Moradi, "A new active snubber cell for DC to DC converter", IEEE transaction on Power Electronics, pp 349-359, 2008.

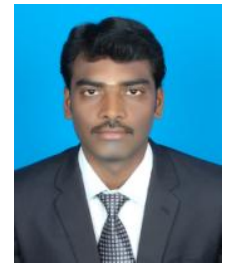

M. ANNAMALAI received the B.E degree in Electrical \& Electronics Engineering from Sathyabama Engineering College, Madras University, and the M.E degree in Power Electronics and its Industrial Drives from Sathyabama University in 2002 and 2005 respectively. He is a research scholar of Sathyabama University, Chennai, India. His research interests are the Power Electronics, Converter and Wind Energy.

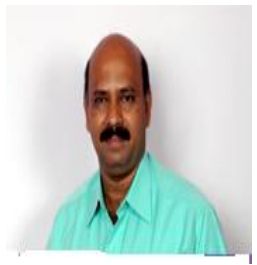

Dr. M. VIJAYA KUMAR received the B.Tech degree in Electrical \& Electronics Engineering from Sri Venkateswara University, Tirupati in 1988 and the M.Tech degree in Electrica Machines \& Industrial Drives from Kakatiya University, Warangal in 1990. He received Ph.D degree from JNT University, Hyderabad in 2000. His research interests are Power Quality and Non Conventional generation.He is professor in Electrical \& Electronics Department, JNTU, Anantapur, Andhra Pradesh, India. 